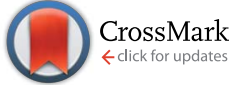

Cite this: RSC Adv., 2017, 7, 3768

\title{
Bio-ethanol production by Zymomonas mobilis using pretreated dairy manure as a carbon and nitrogen source
}

\author{
Yang You, ${ }^{a}$ Song Liu, ${ }^{a}$ Bo Wu, ${ }^{a}$ Yan-Wei Wang, ${ }^{\text {a }}$ Qi-Li Zhu, ${ }^{a}$ Han Qin, ${ }^{a}$ Fu-Rong Tan, ${ }^{a}$ \\ Zhi-Yong Ruan, ${ }^{b}$ Ke-Dong Ma, ${ }^{C}$ Li-Chun Dai, ${ }^{a}$ Min Zhang, ${ }^{a}$ Guo-Quan Hu ${ }^{a}$ \\ and Ming-Xiong $\mathrm{He}^{\star a}$
}

Dairy manure contains high levels of cellulose, hemicellulose and a nitrogen source. These properties make dairy manure a potential biomass source for ethanol production. In this study, a dilute $\mathrm{NaOH}$ pretreatment and enzymatic hydrolysis were carried out for the degradation of lignocellulose from dairy manure. The response surface method and Box-Behnken design were first applied in order to optimize the $\mathrm{NaOH}$ pretreatment. Under the optimization conditions, $21.14 \mathrm{~g} \mathrm{~L}^{-1}$ of glucose and $9.48 \mathrm{~g} \mathrm{~L}^{-1}$ of xylose were obtained from continuous enzymolysis. The maximum ethanol concentration achieved reached $10.55 \mathrm{~g}$ $\mathrm{L}^{-1}$ when using ethanologenic Zymomonas mobilis without an additional nitrogen source. This produced a $71.91 \%$ ethanol yield from manure hydrolysate medium. These results demonstrate the economic benefits of using nitrogen from a dairy manure source for balancing the $\mathrm{C} / \mathrm{N}$ ratio, without the need for an additional nitrogen source. The results from this study could extend beyond cellulosic ethanol for the production of other chemicals.

Received 4th November 2016

Accepted 2nd December 2016

DOI: 10.1039/c6ra26288k

www.rsc.org/advances fact, up to $50 \%$ of the organic $\mathrm{N}$ was found to be converted to ammonium $\left(\mathrm{NH}_{4}-\mathrm{N}\right)$ during the process of $\mathrm{AD}$, while the phosphate content in the digestate was unaffected. ${ }^{2}$ While these biogas residues or the biogas slurry may function as an effective fertilizer for the growth of crops, the concentration of nutrients in the digestate is low, making the cost of transportation relatively high in comparison to conventional fertiliser. Additional significant costs include investments in the storage capacity, which is required due to environmental regulations in numerous countries, including Denmark, Germany, and France. In these countries, not only is the nutrient input perhectare restricted, but the period of application is also limited to the growing season. ${ }^{2}$

Recent studies have been carried out in an attempt to identify other value-added chemicals that are produced from manure. For example, Yao et al. used dairy manure as a nitrogen source, combined with glucose as carbon source. With this mixture, they were able to produce $29.1 \%$ of $\mathrm{L}_{-}(+)$-lactic acid via fermentation by Rhizopus oryzae. ${ }^{3}$ Using pretreated dairy manure as a carbon and nitrogen source, Sun et al. were able to obtain an L-(+)-lactic acid yield of $40.09 \%$ via fermentation by Rhizopus oryzae. ${ }^{4}$ In addition, a three step fermentation process that effectively utilized the nitrogen and the carbohydrate in manure to obtain a fumaric acid yield of $31 \%$ was developed in 2008. ${ }^{5}$ Wang et al. also reported a methodology where digested dairy manure was used as a nutrient supplement for the cultivation of the oil-rich green microalgae, Chlorella sp. ${ }^{6}$ Dairy manure has also been shown to be used for the production of 
cellulase by Trichoderma reesei or a mixed culture containing both T. Reesei and Aspergillus phoenicis. ${ }^{7,8}$

The production of value-added chemicals from dairy manure requires three basic processes. These include pretreatment, enzymatic hydrolysis, and fermentation. Prior to enzymatic hydrolysis, several pretreatment methods have been investigated to identify a method to alter the crystalline structure of the lignocellulose materials for the production of bioethanol and biogas. The alkaline pretreatment of lignocelluloses with $\mathrm{NaOH}$ has been demonstrated to result in the removal or modification of the lignin and increase the biomass porosity. This pretreatment method was found to result in a significant reduction of the crystallinity of cellulose, which could be responsible for improving the activity of enzymatic hydrolyses. ${ }^{9}$ Chen et al. demonstrated that $\mathrm{NaOH}$ loading was the most prevalent variable in enzymatic digestibility. ${ }^{\mathbf{1 0}}$ The statistical optimization by Box-Behnken design of wheat straw pretreated with alkali showed that a $2.5 \% \mathrm{NaOH}$ concentration was very effective in both improving the cellulosic contents and also efficiently disrupting the structure. ${ }^{11} \mathrm{NaOH}$ pretreatment has been considered to be an efficient method for the removal of lignin and the enhancement of the cellulose content. These aspects could be beneficial for the release of greater amounts of fermentable sugar for the production of bio-based materials.

The production of ethanol from a continuously stirred tank reactor (CSTR) anaerobic digester was also investigated. These studies showed CSTR AD fiber to be a suitable biorefining feedstock in comparison to switch grass or corn stover. ${ }^{\mathbf{1 2}}$ Although cellulosic ethanol production has gained popularity recently, with the introduction of several commercial facilities in the last few years, the price of cellulosic ethanol remains an obstacle which limits its global large-scale production. To address this issue, a great deal of research has been focused on developing ways to reduce production costs through the development of a low-cost pretreatment method, ${ }^{\mathbf{1 3 4} 14}$ increased hydrolysis efficiency, robust fermentative microorganisms, and other methods. ${ }^{15-17}$ The addition of nutrients required for microbial cell growth has been demonstrated to be crucial for the efficient fermentation of cellulosic ethanol, which could significantly increase the cost of large-scale production. ${ }^{\mathbf{1 8 , 1 9}}$ In order to further reduce the cost of cellulosic ethanol production, studies may focus on ways to reduce the amount of chemical nutrients added throughout the fermentation process. In addition to seeking cheaper nutrient sources as a substitute for expensive yeast extract, employing biomass enriched in nutrients for ethanol fermentation should also be considered as a potential strategy. Because dairy manure contains cellulose, hemicellulose, nitrogen, ammonia, potassium, phosphorus, and other nutrients, it could be considered as a potential feedstock for bioethanol or other value-added products without any extra nitrogen nutrients added.

While dairy manure contains high levels of cellulose, hemicellulose, and nitrogen, little attention has been paid to utilizing dairy manure as both the nitrogen and carbon source for bioethanol production. Few studies exist which focus on ethanol production from manure, i.e., the process of making alcohol through the fermentation of animal manure mixed with active yeast (EP 0085810 A2). ${ }^{20}$ In addition, few studies have focused on the potential of bio-ethanol production from poultry manure using dilute $\mathrm{H}_{2} \mathrm{SO}_{4}$ hydrolyzed. ${ }^{21}$ In addition, the degradation profiling of manure cellulose and the transforming rule of ammonia nitrogen are also unclear. Because dairy manure is a nutrient enriched material, the potential of its use in bioethanol production is worth considering. This is especially true for the degradation profile of manure cellulose and nitrogen resources utilized during ethanol fermentation. ${ }^{22}$

Zymomonas mobilis possesses numerous valuable characteristics for its special Entner-Doudoroff (ED) pathway, making it an ideal ethanologenic strain to be used for ethanol production. ${ }^{17,23}$ Extensive fundamental studies carried out over the past 30 years have focused on $Z$. mobilis and have demonstrated the promise of this ethanologenic organism for large scale bioethanol production. ${ }^{17}$ Recent studies have also demonstrated that $Z$. mobilis can use $\mathrm{N}_{2}$ as a nitrogen source via its $\mathrm{N}_{2}$ fixation pathway. ${ }^{22}$ Therefore, the current work presented here will investigate the feasibility of ethanol production from dairy manure by $Z$. mobilis. Dilute $\mathrm{NaOH}$ pretreatment and enzymatic hydrolysis were performed, followed fermentate by ethanologenic $Z$. mobilis, in the absence of any additional nitrogen resources. This work will not only enable the development of a deeper understanding of the degradation profile of manure cellulose and nitrogen resources utilized during ethanol fermentation, but will also provide a novel $Z$. mobilis based technology for ethanol production using pretreated dairy manure as a carbon and nitrogen source, without further addition of any additional nutrients. Importantly, preliminary studies regarding the utilization of ammonia nitrogen will also provide insight into nitrogen utilization in the metabolic pathway of $Z$. mobilis. The results from these studies could make $Z$. mobilis a candidate ethanologenic for ethanol production using cheaper nitrogen sources.

\section{Materials and experiments}

\section{Material and preparation}

Fresh dairy manure was obtained from Zheng long farm in Sichuan province and was stored at $4{ }^{\circ} \mathrm{C}$. The original manure was dried at $105^{\circ} \mathrm{C}$ and smashed into tiny particles. These were then passed through a sieved with a 40-mesh screen, blended and packed. The neutral detergent fiber (NDF), acid detergent fiber (ADF), and acid detergent lignin (ADL) of the original manure and pretreated manure were determined by Fibertec 2010 using quartz sand as filter acid. ${ }^{24}$ The content changes of cellulose, hemicellulose and acid detergent lignin reflected the effects of $\mathrm{NaOH}$ pretreatment. Data showing results from the original manure and pretreated manure are shown in Table 1.

\section{Bacterial strains and fermentation conditions}

Z. mobilis ZMT2 ${ }^{25}$ (CGMCC11888, from our lab, stored at China General Microbiological Culture Collection Center) was cultured in Rich media $(\mathrm{RM})^{\mathbf{2 6}}$ at $30{ }^{\circ} \mathrm{C}$ without shaking. Cultures were maintained on glucose agar $\left(20.0 \mathrm{~g} \mathrm{~L}^{-1}\right.$ glucose, $10.0 \mathrm{~g} \mathrm{~L}^{-1}$ yeast extract and $15.0 \mathrm{~g} \mathrm{~L}^{-1}$ agar). Organisms were 
Table 1 Characteristics of sample manures ${ }^{a}$

\begin{tabular}{lrr}
\hline & $\begin{array}{l}\text { Original } \\
\text { manure }\end{array}$ & \multicolumn{1}{c}{$\begin{array}{l}\text { Pretreated } \\
\text { manure }\end{array}$} \\
\hline Dry matter, \% & $20.04 \pm 1.36$ & $25.08 \pm 1.11$ \\
NDF, \% dry matter & $56.39 \pm 0.76$ & $65.91 \pm 2.15$ \\
ADF, \% dry matter & $33.53 \pm 0.91$ & $52.67 \pm 2.15$ \\
ADL, \% dry matter & $8.95 \pm 0.66$ & $7.89 \pm 1.50$ \\
Cellulose $(=\mathrm{ADF}-\mathrm{ADL})$, & $24.57 \pm 1.55$ & $44.78 \pm 1.48$ \\
\% dry matter & & $13.24 \pm 1.26$ \\
Hemicellulose $(=\mathrm{NDF}-\mathrm{ADF})$, & $22.87 \pm 0.31$ & $7.89 \pm 1.50$ \\
\%dry matter & & $1.82 \pm 0.28$ \\
Lignin $(=\mathrm{ADL}), \%$ dry matter & $8.95 \pm 0.66$ & $40.07 \pm 0.68$ \\
$\mathrm{~N}, \%$ dry matter & $2.83 \pm 0.33$ & \\
$\mathrm{C}, \%$ dry matter & $48.00 \pm 0.76$ & \\
${ }^{*}$ All data are the average of triplicates with standard deviations of the \\
means $(n=3)$ at $\alpha=0.05$.
\end{tabular}

subcultured to fresh inoculum media for $24 \mathrm{~h}$ at $30{ }^{\circ} \mathrm{C}$ prior to being inoculated into the fermentation medium. Inoculum medium $\left(\mathrm{g} \mathrm{L}^{-1}\right)$ was comprised of $10.0 \mathrm{~g}$ yeast extract, $1.0 \mathrm{~g}$ $\mathrm{MgCl}_{2}, 1.0 \mathrm{~g}\left(\mathrm{NH}_{4}\right)_{2} \mathrm{SO}_{4}, 1.0 \mathrm{~g} \mathrm{KH}_{2} \mathrm{PO}_{4}$, and $20.0 \mathrm{~g}$ glucose.

\section{Dilute NaOH pretreatment}

The effects of $\mathrm{NaOH}$ concentration, reaction time and temperature on reducing sugar yield. The effects of $\mathrm{NaOH}$ concentration, reaction time and temperature on reducing sugar yield were first investigated using a single factor experimental analysis. ${ }^{\mathbf{1 0}}$ Here, six dilute $\mathrm{NaOH}$ concentrations (from $1 \%$ to $10 \%$ ) were used at six different reaction durations (ranging from $30 \mathrm{~min}$ to $8 \mathrm{~h}$ ) and at six different temperatures (ranging from $90{ }^{\circ} \mathrm{C}$ to $140{ }^{\circ} \mathrm{C}$ ) on original manure. Each of the samples was tested at least three times in duplicate. A defined amount of original dry manure was dissolved in a hydrothermal reaction vessel with $50 \mathrm{~mL}$ of a dilute $\mathrm{NaOH}$ solution, with $1: 10$ solid-liquid ratio. Following pretreatment, the solid-liquid slurry was transferred into a $50 \mathrm{~mL}$ centrifuge tube and was centrifuged at $4500 \mathrm{rpm} \min ^{-1}$ for 3 minutes to separate the liquid from solid. The contents of the supernatant reducing sugar was determined using the 3,5-dinitrosalicylic acid colorimetry method (DNS). ${ }^{27}$ Glucan and xylan contents were calculated based on glucose and xylose concentrations, using anhydro corrections of $0.9 .^{28}$ The reducing sugar yield was calculated as follows:
Table 2 Levels and factors of independent variable used for response surface analysis

\begin{tabular}{llll}
\hline & Levels & \\
\cline { 2 - 4 } Factors & -1 & 0 & 1 \\
\hline Reaction time $(\mathrm{h})$ & 2 & 4 & 6 \\
Temperature $\left({ }^{\circ} \mathrm{C}\right)$ & 100 & 120 & 140 \\
NaOH concentration $(\%, \mathrm{~m} / \mathrm{v})$ & 1 & 2 & 3 \\
Substrate concentration $\left(\mathrm{g} \mathrm{L}^{-1}\right)$ & 100 & 200 & 300 \\
& & & \\
\hline
\end{tabular}

the fixed pretreatment system, high substrate concentration was found to lead to a deficiently mixed solid-liquid due to the hygroscopicity of the dried matter, and the substrate concentration was not taken as a single factor experiment. Three appreciable impact points were selected from the results of each single factor experiment as a response to surface optimization. A three-level-four-factor response surface methodology (RSM) based on the central point replicate was utilized to both measure the reducing sugar yield and optimize the dilute $\mathrm{NaOH}$ pretreatment process. ${ }^{29,30} \mathrm{NaOH}$ concentration $(1 \%, 2 \%, 3 \%)$, reaction time $(2 \mathrm{~h}, 4 \mathrm{~h}, 6 \mathrm{~h})$, temperature $\left(100{ }^{\circ} \mathrm{C}, 120{ }^{\circ} \mathrm{C}\right.$, and $140{ }^{\circ} \mathrm{C}$, respectively), and substrate concentration $\left(100 \mathrm{~g} \mathrm{~L}^{-1}\right.$, $200 \mathrm{~g} \mathrm{~L}^{-1}$, and $300 \mathrm{~g} \mathrm{~L}^{-1}$, respectively) were confirmed respectively. A total of 29 experiments were carried out according to the Box-Behnken design as shown in Tables 2 and $3 .{ }^{31}$ As with the dilute $\mathrm{NaOH}$ pretreatment, the reducing sugar content was measured using the DNS method. For the analysis of these measurements, the statistical model was based on the RSM by linear regression using Design Expert software, version 8.0.6. The solid part was dried at $105{ }^{\circ} \mathrm{C}$ for $5 \mathrm{~h}$ for the subsequent enzymatic hydrolysis reaction.

\section{Tabletop scanning electron microscope analysis}

During the pretreatment process, the structural property of the dairy manure was found to be altered. The TM-1000 was found to be an effective instrument to use for the measurement of this change. It was found that changes observed reached a magnification of 20-10 000. Both the original manure and pretreated manure were dried at $105{ }^{\circ} \mathrm{C}$ for $5 \mathrm{~h}$. These samples were then mounted on conductive double-sided tape and placed on the specimen stub. An image was displayed following the completion of the automatic function with an accelerating voltage of $15 \mathrm{kV} .^{32}$ The different structural changes that were observed between the original manure and pretreated manure will be shown.

$$
\text { Yield of reducing sugar }(\%)=\frac{\text { reducing sugars released } \times 0.9}{\mathrm{DM} \text { dry weight } \times(\text { cellulose }+ \text { hemicellulose }) \text { percentage }} \times 100 \%
$$

\section{Response surface method design for pretreatment optimization}

From the single factor experiment results, the $\mathrm{NaOH}$ concentration, reaction time and temperature were found to have different degrees of effects on the reducing sugar yield. Under

\section{Enzymatic hydrolysis}

Effects of enzyme dosage, substrate concentration and enzymolysis time on reducing sugar yield. The commercial enzyme solution (Sigma, CAS: 9012-54-8) from Trichoderma reesei ATCC 26921 containing 700 units per $g$ was used for the 
Table 3 Three-level-four-factor response surface analyses

\begin{tabular}{|c|c|c|c|c|c|c|c|}
\hline & Run & $\begin{array}{l}\text { Reaction } \\
\text { time } X_{1}(\mathrm{~h})\end{array}$ & $\begin{array}{l}\text { Temperature } \\
X_{2}\left({ }^{\circ} \mathrm{C}\right)\end{array}$ & $\begin{array}{l}\text { Con. of } \mathrm{NaOH} \\
X_{3}(\%)\end{array}$ & $\begin{array}{l}\text { Con. of substrate } \\
X_{4}\left(\mathrm{~g} \mathrm{~L}^{-1}\right)\end{array}$ & \multicolumn{2}{|c|}{ Response reducing sugar yield (\%) } \\
\hline 26 & 2 & 4 & 120 & 2 & 200 & 2.79 & 2.79 \\
\hline 21 & 3 & 4 & 100 & 2 & 100 & 3.14 & 3.15 \\
\hline 2 & 4 & 6 & 100 & 2 & 200 & 2.71 & 2.66 \\
\hline 17 & 7 & 2 & 120 & 1 & 200 & 2.00 & 2.21 \\
\hline 8 & 8 & 4 & 120 & 3 & 300 & 2.51 & 2.37 \\
\hline 15 & 9 & 4 & 100 & 3 & 200 & 2.68 & 2.77 \\
\hline 1 & 10 & 2 & 100 & 2 & 200 & 2.33 & 2.51 \\
\hline 12 & 11 & 6 & 120 & 2 & 300 & 2.36 & 2.48 \\
\hline 5 & 12 & 4 & 120 & 1 & 100 & 3.19 & 3.24 \\
\hline 4 & 17 & 6 & 140 & 2 & 200 & 3.55 & 3.29 \\
\hline 18 & 18 & 6 & 120 & 1 & 200 & 2.45 & 2.62 \\
\hline 29 & 19 & 4 & 120 & 2 & 200 & 2.86 & 2.79 \\
\hline 24 & 20 & 4 & 140 & 2 & 300 & 2.34 & 2.42 \\
\hline 13 & 21 & 4 & 100 & 1 & 200 & 2.27 & 1.94 \\
\hline 14 & 22 & 4 & 140 & 1 & 200 & 2.99 & 2.91 \\
\hline 16 & 23 & 4 & 140 & 3 & 200 & 2.28 & 2.61 \\
\hline 9 & 24 & 2 & 120 & 2 & 100 & 3.37 & 3.25 \\
\hline 10 & 25 & 6 & 120 & 2 & 100 & 3.49 & 3.63 \\
\hline 28 & 26 & 4 & 120 & 2 & 200 & 2.66 & 2.79 \\
\hline 7 & 27 & 4 & 120 & 1 & 300 & 1.78 & 1.76 \\
\hline 23 & 28 & 4 & 100 & 2 & 300 & 2.09 & 2.19 \\
\hline 25 & 29 & 4 & 120 & 2 & 200 & 2.90 & 2.79 \\
\hline
\end{tabular}

enzymatic hydrolysis reaction. An aqueous solution with a density of $1.2 \mathrm{~g} \mathrm{~mL}^{-1}$ at $25^{\circ} \mathrm{C}$ was used, which means that the enzyme activity was $840 \mathrm{U} \mathrm{mL}^{-1}$. One unit is defined as the amount of enzyme required to release $1 \mu \mathrm{g}$ of glucose equivalents from the given substrate, such as filter paper, soluble carboxymethyl cellulose, or degreasing cotton, in $1 \mathrm{~min}$ at $50{ }^{\circ} \mathrm{C}$ and $\mathrm{pH}$ 4.8. Cellulase is a type of compound enzyme class, including $\beta$-endoglucanase, $\beta$-exoglucanase, $\beta$-glucosidase, and xylanase. This enzyme converts cellulose and hemicellulose into glucose and xylose, respectively. The enzyme activity has been demonstrated to depend on $\mathrm{pH}$ and temperature. Enzymatic hydrolysis reactions were carried out in $100 \mathrm{~mL}$ Erlenmeyer flasks containing $30 \mathrm{~mL}$ of $50 \mathrm{mM}$ sodium citrate buffer solution at $\mathrm{pH}$ 4.8. The flasks were incubated in a $50{ }^{\circ} \mathrm{C}$ incubator shaker at $120 \mathrm{rpm}$. The effects of enzyme dosage (84-280 U cellulase per $\mathrm{g}$ pretreated manure), enzymolysis time (12-96 h), and substrate concentration (10-60 $\left.\mathrm{g} \mathrm{L}^{-1}\right)$, and were tested as three single factor experiments in an effort to optimize glucose yield. Considering that the sugar yield will be increased under conditions with excess enzyme concentration and increased enzymolysis time, the single factor experiment to examine enzymatic hydrolysis was carried out under the setting and economic condition to optimize enzyme hydrolysis conditions in the absence of combinatory analysis. Following enzymatic hydrolysis, the solutions were heated to $100{ }^{\circ} \mathrm{C}$ for $5 \mathrm{~min}$ in order to denature the enzymes. The reducing sugar yield was also calculated using the DNS method.

Monosaccharides analysis. The reducing sugar yield in the supernatant was analyzed by DNS, while the monosaccharide composition was determined by the comparison of retention time with standards using High Performance Liquid Chromatography (HPLC). An HPX-87H ion exclusion column (BioRadAminex) was used at $35{ }^{\circ} \mathrm{C}$ with $5 \mathrm{mM} \mathrm{H}_{2} \mathrm{SO}_{4}$ as a mobile phase. A flow rate of $0.6 \mathrm{~mL} \mathrm{~min}^{-1}$ and an injection volume of $20 \mu \mathrm{L}$ were used with a $30 \mathrm{~min}$ analysis time.

Continuous enzymatic hydrolysis. According to the optimum conditions found for enzymatic hydrolysis, the experiment of continuous enzymolysis was also carried out in order to identify a method to enhance the sugar concentration for ethanol production. Thirty-grams of pretreated manure mixed with a suitable amount of cellulase were added as substrate to 100 $\mathrm{mL}$ of sodium citrate buffer solution. Chloramphenicol was also added in order to prevent microbial contamination. Under the reaction conditions of $50{ }^{\circ} \mathrm{C}$ and $120 \mathrm{rpm}$, a $93 \mathrm{~h}$ continuous enzymolysis time was carried out in a $250 \mathrm{~mL}$ triangle bottle. The substrate and enzyme was divided into four parts, and was added in every $3 \mathrm{~h}$ primitively. The sugar yield was determined by HPLC. 


\section{Ethanol fermentation}

In order to estimate the fermentation potential of the continuous enzymatic hydrolysate, $Z$. mobilis ZMT2 was chosen as the fermentation strain for ethanol production. ${ }^{25}$ Before inoculation, the continuous enzymatic hydrolysate was sterilized using as eptic membrane filtration. In addition, the RM medium was used as a control for the comparison of utilizing carbon and nitrogen during ethanol fermentation. Using a 10\% inoculation concentration, the fermentation experiment was carried out at $30{ }^{\circ} \mathrm{C}$ without shaking. HPLC was used to analyze the glucose consumption and ethanol yield using the following equation: ${ }^{33}$ maximum reducing sugar yield of $3.37 \%$ (88.8 $\mathrm{mg}$ reducing sugar/5 g dry manure) was achieved when a $6 \% \mathrm{NaOH}$ concentration was used. Any further increase in alkali concentration provided only a minor influence on the reducing sugar recovery. For economical considerations, three different $\mathrm{NaOH}$ concentrations $(1 \%, 2 \%$, and $3 \%, w / v)$ were selected for response surface optimization.

Next, the effect of the reaction time on sugar recovery was examined. In these experiments, the reaction time ranged from $0.5 \mathrm{~h}$ to $8 \mathrm{~h}$, with a fixed substrate concentration of $100 \mathrm{~g} \mathrm{~L}^{-1}$, a fixed temperature of $120{ }^{\circ} \mathrm{C}$, and a fixed $4 \% \mathrm{NaOH}$ concentration. As shown in Fig. 1(b), the reducing sugar yield was

$$
\text { Ethanol yield }(\%)=\frac{\text { final ethanol concentration }\left(\mathrm{g} \mathrm{L}^{-1}\right)}{\text { initial glucose and xylose concentration } \times 0.511\left(\mathrm{~g} \mathrm{~L}^{-1}\right)} \times 100 \%
$$

\section{Analysis of nitrogen content}

The nitrogen content in pretreated, enzymatic hydrolysis, and fermentation solutions were analyzed by a spectrophotometric method, using an auto analyzer (AA3, Bran + Luebbe, Norderstedt, Germany). ${ }^{34}$

\section{Results and discussion}

\section{Characterization of raw manure}

The characterization of raw manure and $\mathrm{NaOH}$-pretreated manure solids are presented in Table 1. Lignocellulosics (hemicellulose, cellulose and lignin) were found to account or $56.39 \%$ of the raw manure dry matter. Following $\mathrm{NaOH}$ pretreatment, the cellulose fraction was found to increase by $20 \%$, from $24.57 \%$ to $44.78 \%$. This observed increase is higher than the previous report of $35.67 \% .{ }^{35}$ On the other hand, we observed a slight decrease in lignin and a significant decrease of hemicellulose. This indicates that the $\mathrm{NaOH}$ pretreatment efficiently disrupted the manure structure, reducing its crystallinity. The cellulose degradation process produces glucose, while the degradation of hemicellulose produces xylose. A high proportion of cellulose indicates that the protocol can be further optimized to produce more glucose.

\section{Dilute NaOH pretreatment}

Effects of $\mathrm{NaOH}$ concentration, reaction time and temperature on reducing sugar yield. A reduction in sugar yield was found to correlate with increasing $\mathrm{NaOH}$ concentration, reaction time, and temperature. The $\mathrm{NaOH}$ pretreatment was found to have a positive effect on reducing the sugar yield, as depicted in Fig. 1.

The single factor experiment examining the effect of $\mathrm{NaOH}$ concentration was carried out first at $120^{\circ} \mathrm{C}$ for $2 \mathrm{~h}$, with an initial $100 \mathrm{~g} \mathrm{~L}^{-1}$ substrate concentration used, as shown in Fig. 1(a). Under conditions with $1 \% \mathrm{NaOH}(\mathrm{w} / \mathrm{v})$, the reducing sugar yield was calculated to be $2.90 \%$ (76.5 $\mathrm{mg}$ reducing sugar/ $5 \mathrm{~g}$ dry manure), which was nearly twice that of the $1.57 \%$ calculated with pure water pretreatment conditions. The observed to rapidly increase from $2.70 \%$ (71 $\mathrm{mg}$ reducing sugar/ $5 \mathrm{~g}$ dry manure) at $0.5 \mathrm{~h}$ to $4.08 \%$ (107.5 $\mathrm{mg}$ reducing sugar $/ 5 \mathrm{~g}$ dry manure) at $4 \mathrm{~h}$. From $0.5 \mathrm{~h}$ to $4 \mathrm{~h}$, the reducing sugar yield was found to increase to $1.38 \%$, where it then stabilized. Only a $0.03 \%$ increase was observed when the reaction time was increased from $4 \mathrm{~h}$ to $8 \mathrm{~h}$, with a reducing sugar yield of $4.11 \%$ (108.5 $\mathrm{mg}$ reducing sugar/5 $\mathrm{g}$ dry manure) at $8 \mathrm{~h}$. These results demonstrate that $\mathrm{NaOH}$ treatment within $4 \mathrm{~h}$ was sufficient for reducing sugar recovery from dairy manure.

Finally, the effect of temperature on reducing the sugar yield was studied by examining six different temperatures, ranging from $90{ }^{\circ} \mathrm{C}$ to $140{ }^{\circ} \mathrm{C}$. These experiments were carried out with a $4 \mathrm{~h}$ reaction time, a $100 \mathrm{~g} \mathrm{~L}^{-1}$ substrate concentration, and a $4 \% \mathrm{NaOH}$ concentration. The trend of reducing sugar yield changes with temperature was similar to that observed with changes in the reaction time. As shown in Fig. 1(c), the reducing sugar yield was raised from $3.21 \%$ (84.5 mg reducing sugar $/ 5 \mathrm{~g}$ dry manure) at $90{ }^{\circ} \mathrm{C}$ to $4.08 \%$ (107.5 $\mathrm{mg}$ reducing sugar $/ 5 \mathrm{~g}$ dry manure) at $120{ }^{\circ} \mathrm{C}$. However, when the temperature was increased from $120{ }^{\circ} \mathrm{C}$ to $140{ }^{\circ} \mathrm{C}$, the reducing sugar yield was found to increase by only $0.10 \%$. This suggests that the browning reaction occurred slowly at high temperatures. Higher temperature pretreatment combined with $\mathrm{NaOH}$ solution were found to effectively eliminate fiber crystallization.

Response surface analysis (RSA). In order to optimize the effect of factors on reducing sugar yield, we performed a central composite design (CCD) with four factors at three levels. Table 2 shows the actual values of the different combinations used for this response surface methodology. The central composite design was also applied using Design-Expert 8.0.6 software. According to the design, a total of 29 experiments with four factors were generated, as depicted in Table 3 . The actual value and the predicted value on the response for reducing sugar yield were very similar. The variance analysis (ANOVA) shows that the model $F$-value of 10.37 implies that the model in Table 4 is significant. Specifically, there is only a $0.01 \%$ chance that a "Model $F$-Value" this large could occur due to noise. Values of "Prob $>F$ " less than 0.05 indicate model terms were significant. ${ }^{11}$ In this case, $X_{1}, X_{2}, X_{3}, X_{4}, X_{2} X_{3}, X_{3}{ }^{2}$ were significant 

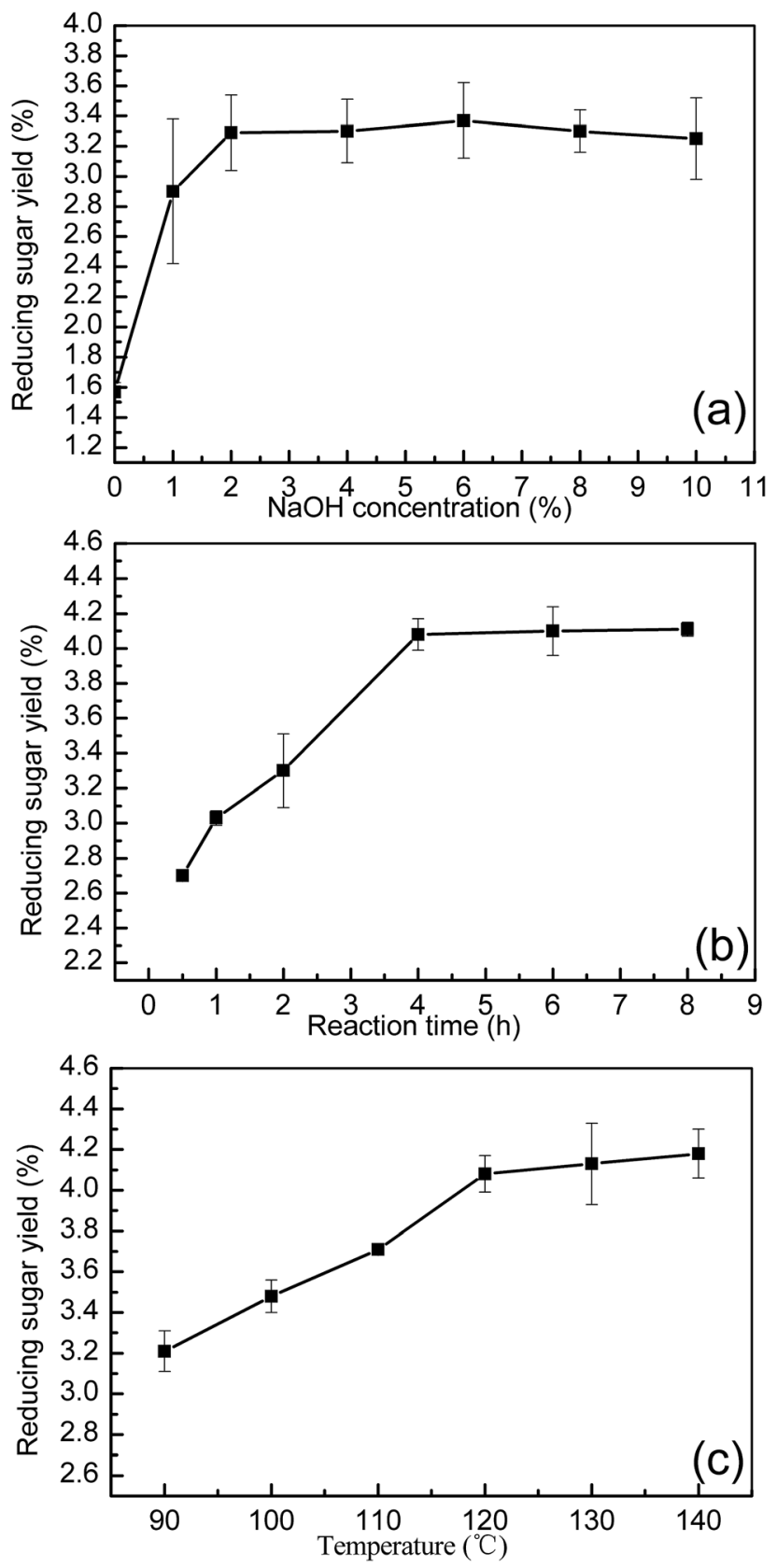

Fig. 1 Effects of (a) $\mathrm{NaOH}$ concentration, (b) reaction time and (c) temperature on reducing sugar. Data presented as the mean of replicates with standard deviation.

model terms. Values greater than 0.10 indicate the model terms were not significant. More than $91 \%$ of the sample variation could be attributed to the variables as determined by the $R^{2}$ value. Considering the single factor, the sequence of effects on the reducing sugar yield were $X_{4}>X_{2}>X_{1}>X_{3}$, while the interaction effect sequence was $X_{2} X_{3}>X_{3} X_{4}>X_{1} X_{2}>X_{2} X_{4}>X_{1} X_{3}$ $>X_{1} X_{4}$. The interaction effects on the reducing sugar yield are shown in Fig. 2. The multiple quadratic response surface regression model should cover all of the variables and coefficients while using Design-Expert software for quadratic regression analysis. From this, we obtained the following model:
Reducing sugar yield $(\%)=-1.04667-0.19750 X_{1}+0.034917 X_{2}$

$+2.46167 X_{3}-0.068333 X_{4}+2.68750 \times 10^{-3} X_{1} X_{2}$

$-0.010000 X_{1} X_{3}-1.25000 \times 10^{-4} X_{1} X_{4}-0.014000 X_{2} X_{3}$

$-4.62500 \times 10^{-4} X_{2} X_{4}+0.017000 X_{3} X_{4}-1.14583 \times 10^{-3} X_{1}{ }^{2}$

$+7.29167 \times 10^{-6} X_{2}^{2}-0.23708 X_{3}^{2}+8.29167 \times 10^{-4} X_{4}^{2}$.

Where, $X_{1}, X_{2}, X_{3}$, and $X_{4}$ refer to the reaction time, temperature, $\mathrm{NaOH}$ concentration, and substrate concentration, respectively.

On the basis of CCD from Box-Behnken and the theory of response surface analysis, the optimal conditions were determined to be a $6 \mathrm{~h}$ reaction time, $140{ }^{\circ} \mathrm{C}$, a $1.34 \% \mathrm{NaOH}$ concentration, and a $100 \mathrm{~g} \mathrm{~L}^{-1}$ substrate concentration. Under these optimal conditions, a reducing sugar yield of $4.15 \%$ (109.4 mg reducing sugar/5 g dry manure) was achieved. A verification test demonstrated similar results, with a reducing sugar yield of $4.14 \%$ (109.1 $\mathrm{mg}$ reducing sugar/5 $\mathrm{g}$ dry manure). These results demonstrate that the response surface method is both feasible and suitable for reducing sugar yield analysis under these conditions.

Tabletop scanning electron microscope analysis. The structural changes present between untreated manure and $\mathrm{NaOH}$ pretreated manure were further analyzed using TM. As depicted in Fig. 3, the fiber structure of untreated manure appeared to be rougher than the $\mathrm{NaOH}$ pretreated manure. In addition, we observed that more substances were attached to the surface. These substances have previously been reported to be nitrogenrelated materials. Another difference observed was that in the case of manure pretreated with $\mathrm{NaOH}$, some holes were visualized on the fiber structure surface, while the fiber stripe was also found to be thinner. The observations made from these studies demonstrate that an alkali pretreatment efficiently breaks down the crystalline structure of fiber, resulting in hemicelluloses degradation, and the removal of lignin to expose cellulose.

\section{Enzymatic hydrolysis}

Effects of enzyme dosage, substrate concentration and enzymolysis time on reducing sugar yield. In order to obtain the maximal sugar yield and reduce the cost of biofuel production, the enzymatic hydrolysis conditions were optimized in terms of enzyme dosage, substrate concentration, and enzyme reaction time. As depicted in Fig. 4(a), the reducing sugar yield was found to decrease with increasing substrate concentration. The maximum sugar yield of $44.3 \%$ (85.8 $\mathrm{mg}$ reducing sugar/0.3 $\mathrm{g}$ pretreated manure) was obtained with a $10 \mathrm{~g} \mathrm{~L}^{-1}$ substrate concentration. Higher substrate concentrations were found to have a negative effect on sugar recovery, with a $17.6 \%$ sugar yield obtained using a $60 \mathrm{~g} \mathrm{~L} \mathrm{~L}^{-1}$ substrate concentration (204.8 $\mathrm{mg}$ reducing sugar/1.8 g pretreated manure). This could be explained by the fact that high substrate concentration could inhibit contact between the enzyme and substrate, resulting in decreased enzyme activity.

Fig. 4(b) shows the effect of enzyme reaction time on sugar yield. The reducing sugar yield was found to increase from 
Table 4 The variance analysis of response surface

\begin{tabular}{llllll}
\hline Source & Sum of squares & df & Mean square & $F$-Value & $P$-Value Prob $>F$ \\
\hline Model & 6.04 & 14 & 0.43 & 10.37 & $<0.0001$ \\
$X_{1}$-Reaction time & 0.42 & 1 & 0.42 & 10.05 & 0.0068 \\
$X_{2}$-Temperature & 0.50 & 1 & 0.50 & 11.92 & 0.0039 \\
$X_{3}$-NaOH concentration & 0.21 & 1 & 0.21 & 5.13 & 0.0400 \\
$X_{4}$-Substrate concentration & 3.92 & 1 & 3.92 & 94.25 & $<0.0001$ \\
$X_{1} X_{2}$ & 0.046 & 1 & 0.046 & 1.11 & 0.3097 \\
$X_{1} X_{3}$ & 0.0016 & 1 & 0.0016 & 0.038 & 0.8474 \\
$X_{1} X_{4}$ & 0.000025 & 1 & 0.000025 & 0.0006008 & 0.9808 \\
$X_{2} X_{3}$ & 0.31 & 1 & 0.31 & 7.54 & 0.0158 \\
$X_{2} X_{4}$ & 0.034 & 1 & 0.034 & 0.82 & 0.3798 \\
$X_{3} X_{4}$ & 0.12 & 1 & 0.12 & 2.78 & 0.1178 \\
$X_{1}{ }^{2}$ & 0.0001363 & 1 & 0.0001363 & 0.003275 & 0.9552 \\
$X_{2}{ }^{2}$ & 0.00005518 & 1 & 0.00005518 & 0.001326 & 0.9715 \\
$X_{3}{ }^{2}$ & 0.36 & 1 & 0.36 & 8.76 & 0.0103 \\
$X_{4}$ & 0.045 & 1 & 0.045 & 1.07 & 0.3181 \\
Residual & 0.58 & 14 & 0.042 & & 0.0495 \\
Lack of fit & 0.55 & 10 & 0.055 & 6.00 & Significant \\
Pure error & 0.036 & 4 & 0.0091 & & \\
Cor total & 6.62 & 28 & & & \\
& & & & & \\
\hline
\end{tabular}

$27.1 \%$ (52.5 $\mathrm{mg}$ reducing sugar/0.3 g pretreated manure) to $53.1 \%$ (102.9 $\mathrm{mg}$ reducing sugar/0.3 g pretreated manure). The increase in the enzyme reaction time was found to result in a clear increase in the yield of reducing sugar. However, a further increase in the reaction time was found to have no obvious effect on the reducing sugar yield. After $72 \mathrm{~h}$, the reducing sugar yield trend stabilized. These results indicate that a $72 \mathrm{~h}$ reaction time enables the concentration of reducing sugar to reach $3.4 \mathrm{~g} \mathrm{~L}^{-1}$, with longer reaction times not providing any further sugar release.

Cellulase was found to play a key role in the enzymatic hydrolysis reaction that influences the reducing sugar yield. The effect of enzyme dosage on reducing sugar yield is shown in Fig. 4(c). Under conditions where a $10 \mathrm{~g} \mathrm{~L}^{-1}$ substrate concentration was used, an increased dosage of enzyme (from $84 \mathrm{U}$ to $196 \mathrm{U}$ cellulase per $\mathrm{g}$ pretreated manure) was found to increase cellulose degradation, increasing the reducing sugar yield from $35.3 \%$ (68.5 $\mathrm{mg}$ reducing sugar/0.3 $\mathrm{g}$ pretreated manure) to $55.5 \%$ (107.5 g reducing sugar/0.3 g pretreated manure). However, when the cellulase dosage was greater than $196 \mathrm{U} \mathrm{g}^{-1}$ pretreated manure, the reducing sugar yield was found to have only a small decrease of $2.55 \%$. This observation could be potentially explained by end-product inhibition. With lower enzyme dosages, the sugar concentration did not reach the maximum. However, when the enzyme dosage was higher than 196 U cellulase per $g$ pretreated manure, the high concentration of sugars were found to have an inhibitory effect on cellulase activity.

Based on results from the single factor experiment analysis, the ideal enzymatic hydrolysis conditions were determined to be the following: a $10 \mathrm{~g} \mathrm{~L}^{-1}$ substrate concentration, a $72 \mathrm{~h}$ enzyme reaction time, and a $196 \mathrm{U} \mathrm{g}^{-1}$ pretreated manure cellulase dosage.

Monosaccharides analysis. The monosaccharide composition analysis was also examined using a single factor experiment with a $196 \mathrm{U}$ cellulase per $\mathrm{g}$ pretreated manure enzyme dosage, a $48 \mathrm{~h}$ reaction time, and a 1\% substrate concentration. The results from these experiments demonstrated that the enzymatic hydrolysate contained primarily cellobiose, glucose, and xylose. Glucose and cellobiose were generated from cellulose hydrolysis, while xylose was generated from the hydrolysis of hemicellulose. Because of the reaction time in these experiments, the cellulose was inadequately hydrolyzed, resulting in the production of cellobiose, a product that cannot be utilized for ethanol production by microorganisms. This observation indicates that enzymatic hydrolysis requires a specific amount of time for the hydrolysis of one mole of cellobiose into two moles of glucose, as the enzymatic hydrolysate contained only a single glucose and xylose following complete hydrolysis. In an additional study, $115.6 \mathrm{~g} \mathrm{~L}^{-1}$ glucose was produced under conditions where $0.8 \mathrm{M}$ dilute $\mathrm{H}_{2} \mathrm{SO}_{4}$ was hydrolyzed at $130{ }^{\circ} \mathrm{C}$, with a $30 \mathrm{~min}$ hydrolysis reaction time, without cellulase enzymatic hydrolysis. ${ }^{21}$ However, the degradation profile of manure cellulose was not shown in this study.

Continuous enzymatics. Under the optimum enzymatic hydrolysis conditions, the total concentration of reducing sugar was found to increase with increasing enzymatic reaction times, reaching $41 \mathrm{~g} \mathrm{~L}^{-1}$ at $93 \mathrm{~h}$. As shown in Fig. 5, the concentrations of glucose and xylose rapidly increased with in $9 \mathrm{~h}$, reaching close to half of the total output. After $9 \mathrm{~h}$, the glucose and xylose concentrations continued to slowly increase until $93 \mathrm{~h}$. Upon completion of the continuous enzymolysis, the glucose and xylose concentrations were measured to be $21.14 \mathrm{~g} \mathrm{~L}^{-1}$ and $9.48 \mathrm{~g} \mathrm{~L}^{-1}$, respectively. These results indicate that the process of continuous enzymolysis could enhance the concentrations of glucose and xylose, and could be suitable for fermentation.

Ethanol fermentation analysis. Ethanol fermentation by $Z$. mobilis ZMT2 was carried out using hydrolysate as a substrate, and RM medium was used as a control. Z. mobilis ZMT2 possesses a unique Entner-Doudoroff metabolic pathway for 
(a)

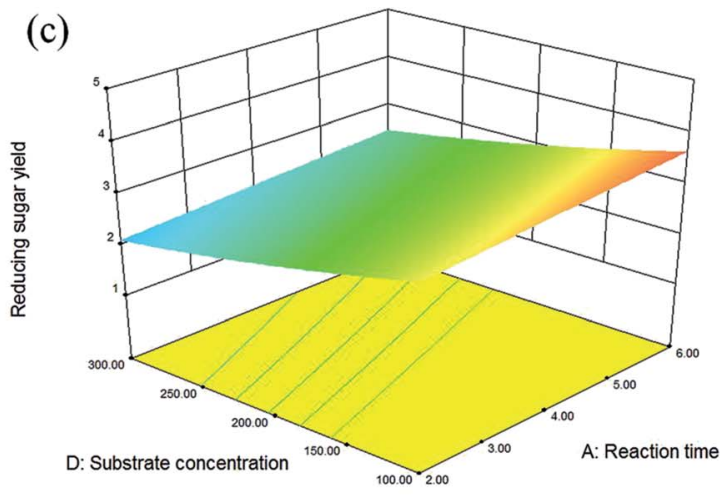

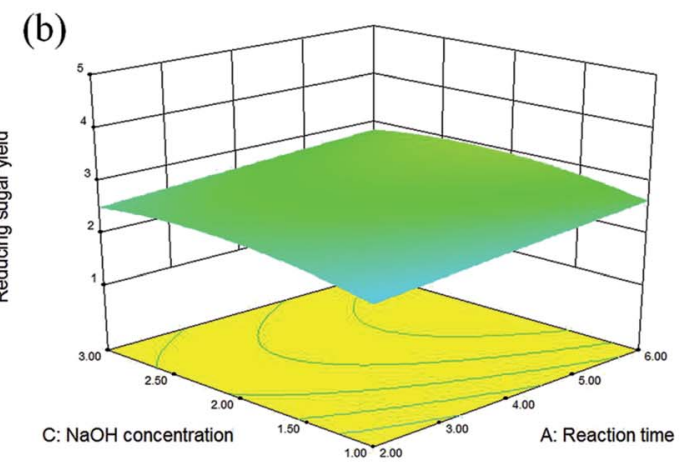
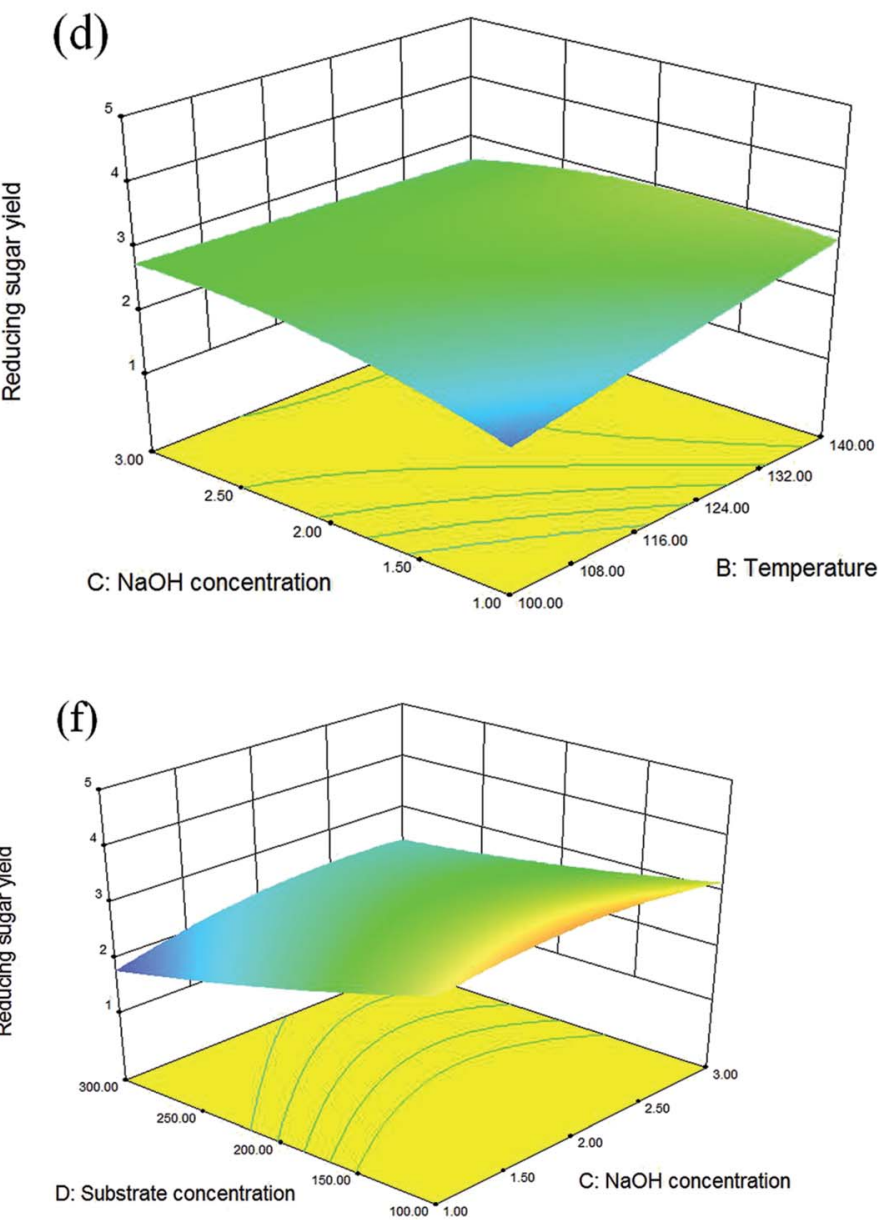

Fig. 2 Three dimension surface plot analysis of the effect of different treatment combination on reducing sugar yield. (a) Reaction time and temperature, (b) reaction time and $\mathrm{NaOH}$ concentration, (c) reaction time and substrate concentration, (d) temperature and $\mathrm{NaOH}$ concentration, (e) temperature and substrate concentration and (f) $\mathrm{NaOH}$ concentration and substrate concentration.

the anaerobic fermentation of hexose for ethanol production. Substrates for this pathway include glucose, fructose and sucrose, but not pentose. As shown in Fig. 6(a), a $20 \mathrm{~g} \mathrm{~L}^{-1}$ concentration of glucose was completely consumed and produced a $9.6 \mathrm{~g} \mathrm{~L}^{-1}$ ethanol yield within $12 \mathrm{~h}$ in $\mathrm{RM}$ medium. The total amount of glucose depleted in $48 \mathrm{~h}$ to generate $10.55 \mathrm{~g}$ $\mathrm{L}^{-1}$ ethanol and a $71.91 \%$ ethanol yield in manure hydrolysate medium is presented in Fig. 6(b). The slower glucose conversion rate observed in hydrolysate medium could be due to the presence of inhibitors that exist in the medium, or were possibly produced by the $\mathrm{NaOH}$ pretreatment. This phenomenon should be examined further in future studies. Alternatively, the limitations on the sugars utilized by Z. mobilis ZMT2 in this study, such as pentose and xylose which cannot be consumed in the continuous enzymatic hydrolysate for ethanol fermentation, could also lead to a decreased theoretical ethanol yield. ${ }^{17}$ 

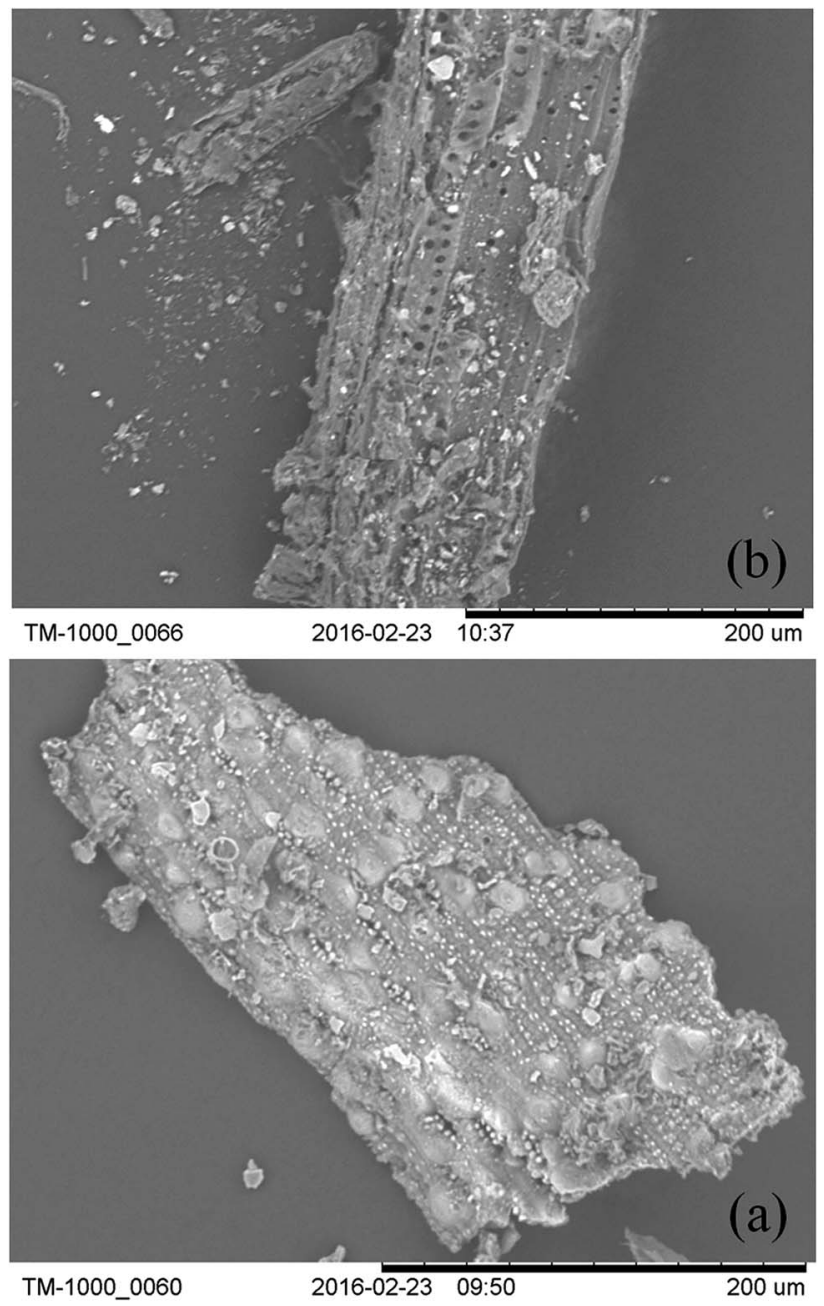

Fig. 3 Tabletop microscope of daily manure $(500 \times)$. (a) Original daily manure and (b) pretreated manure $\left(6 \mathrm{~h}, 140{ }^{\circ} \mathrm{C}, 1.34 \% \mathrm{NaOH}\right.$ and $100 \mathrm{~g}$ $\mathrm{L}^{-1}$ substrate concentration).

Microbial growth and metabolism require an adequate nitrogen source. In our fermentation experiments, the nitrogen content in pretreated manure hydrolysate was reduced from $108.2 \mathrm{mg} \mathrm{L}^{-1}$ to $57.0 \mathrm{mg} \mathrm{L}^{-1}$, indicating that $47.3 \%$ of the nitrogen source had been consumed by Z. mobilis ZMT2 for cell growth and metabolism (as shown in Fig. 7). In comparison with results shown in Fig. 6(a), Z. mobilis ZMT2 was found to be able to ferment manure hydrolysate for ethanol production in the absence of an additional nitrogen source. This indicates that the nitrogen content in the enzymatic hydrolysate was sufficient for Z. mobilis growth and metabolism. While previous studies have reported the ability to produce ethanol from animal manure, ${ }^{20,21}$ the transforming rule of ammonia nitrogen was unclear in these studies. In our current work, we first show that some ammonia nitrogen resources exist in manure, which may be utilized as a nitrogen source for ethanol production. Following fermentation, $47.3 \%$ of the nitrogen source was found to be consumed by $Z$. mobilis. The preliminary study regarding ammonia nitrogen utilization in $Z$. mobilis will provide insight into the nitrogen utilization metabolic pathway.
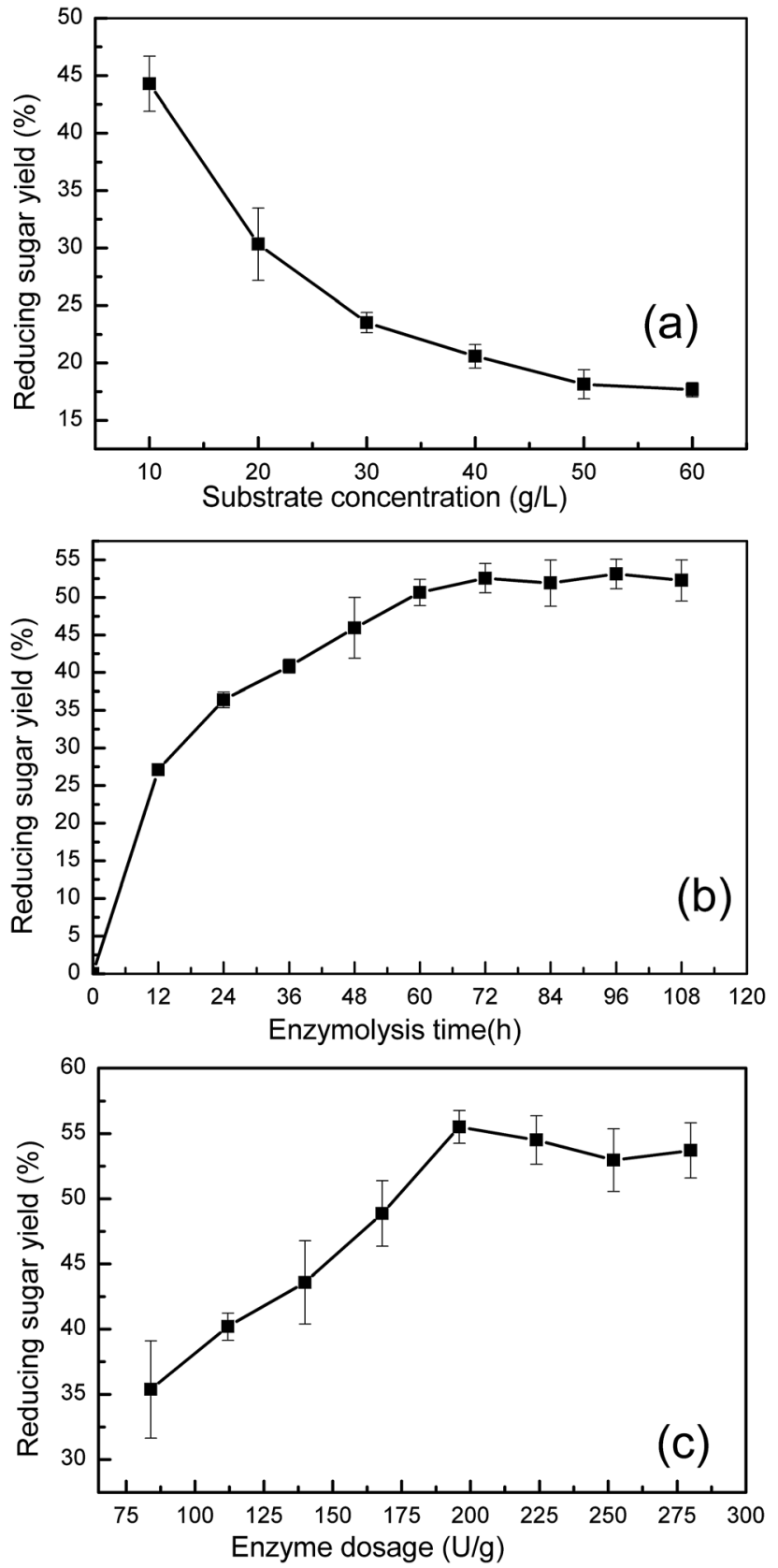

Fig. 4 Effects of (a) substrate concentration, (b) enzymolysis time and (c) enzyme dosage on reducing sugar yield. Data showed as the mean of replicates with standard deviation.

It is important to note that other industrial nitrogen sources used for cellulosic ethanol, i.e. corn steep liquor (CSL), diammonium phosphate (DAP), have been estimated to incur costs between $\$ 1.7$ and 2.2 million per year in a 200 million liter ethanol plant. ${ }^{18,19}$ Thus, a sustainable alternative nitrogen source is desirable. In our current study, dairy manure was shown to provide not only a fermentable sugar, but also an adequate nitrogen source for ethanol production. This source will provide a new candidate biomass resource for the production of ethanol or other chemicals in the future. Furthermore, we also speculate that the addition of dairy manure could also 


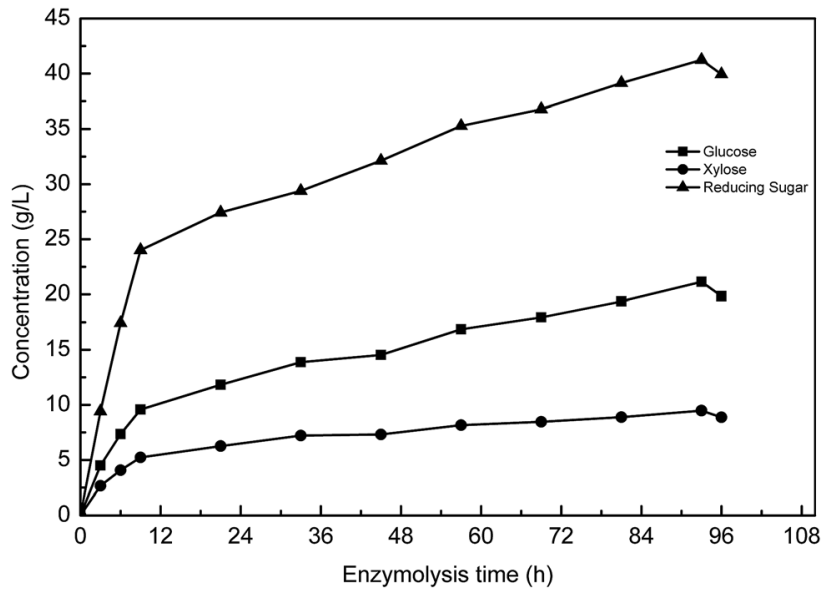

Fig. 5 Changes of reducing sugar, glucose and xylose in the continuous enzymolysis process.
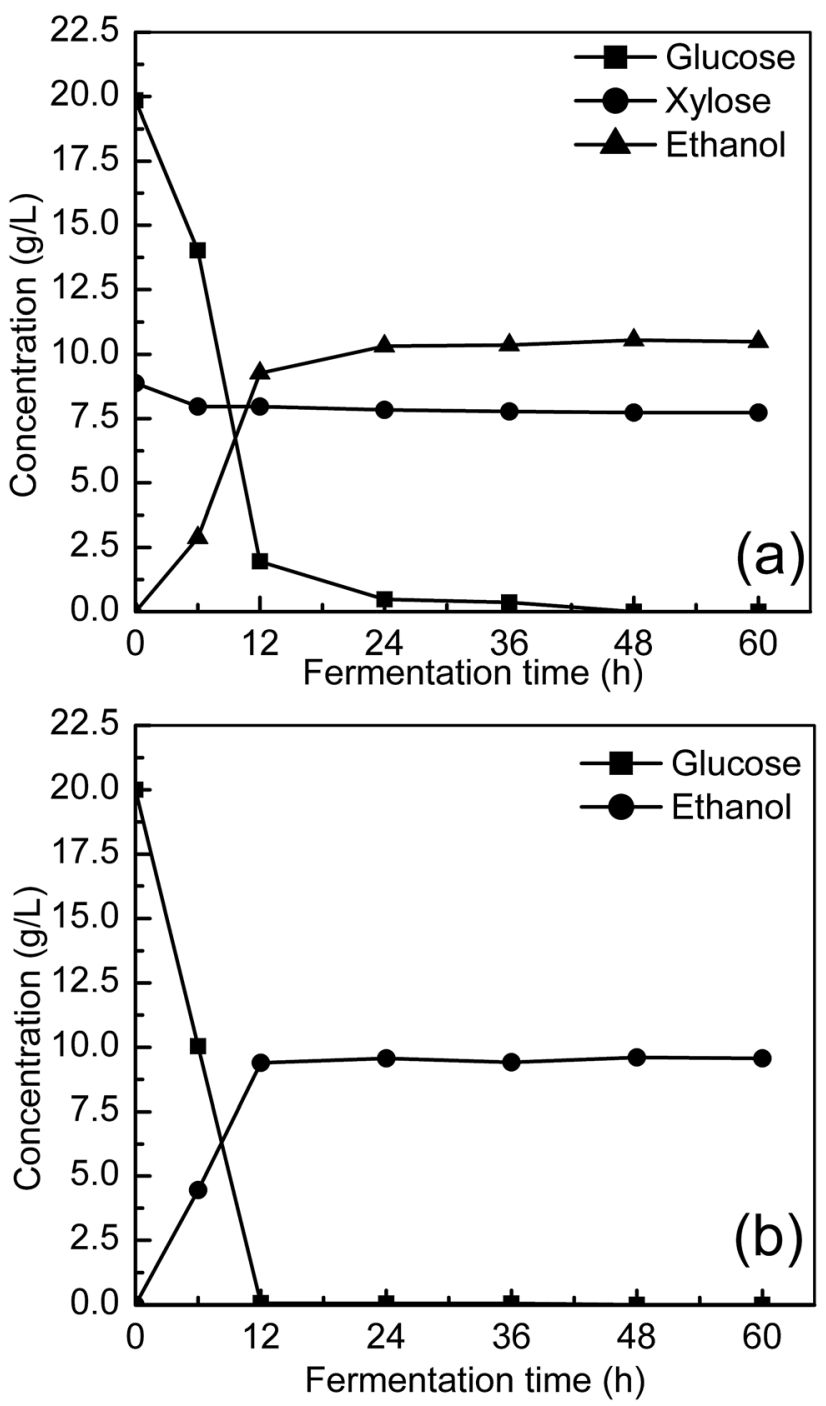

Fig. 6 Ethanol fermentation using continuous enzymatic hydrolysate by Z. mobilis ZMT2. (a) Continuous enzymatic hydrolysate fermentation, and (b) RM medium control.

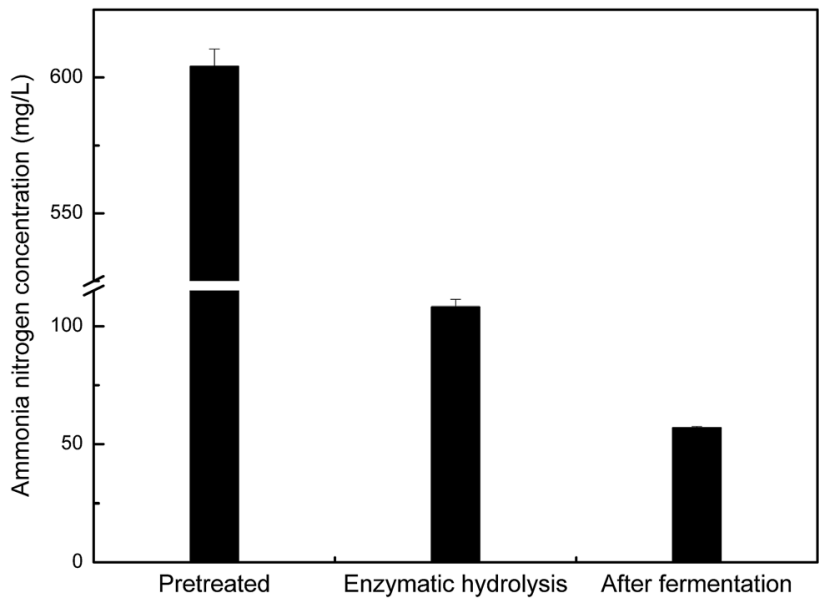

Fig. 7 The nitrogen content in the pretreated, enzymatic hydrolysis, and fermentation solution.

be used in the process of cellulosic ethanol production for balancing the $\mathrm{C} / \mathrm{N}$ ratio, without the need for any additional nitrogen source. Thus, the economic benefits of nitrogen from dairy manure could extend beyond cellulosic ethanol to the production of other chemicals.

Interestingly, previous studies have also indicated that $Z$. mobilis could utilize $\mathrm{N}_{2}$ as a nitrogen source via the $\mathrm{N}_{2}$ fixation pathway. ${ }^{22}$ In a cellulosic feedstock-derived medium, Z. mobilis was demonstrated to achieve a similar cell density and a slightly higher ethanol yield when provided with $\mathrm{N}_{2}$ instead of the industrial nitrogen supplement. ${ }^{22}$ Genomic evidence also demonstrates the presence of a $\mathrm{N}_{2}$ fixation pathway in $Z$. mobilis, with the identification of some genes that are potentially involved in nitrogenase function and regulation including nifH (ZMO1823), nifK (ZMO1824), and nifD (ZMO1825). The gene (ZMO0493), which encodes glutamine synthetase, along with two genes (ZMO1116 and ZMO1117) that encode glutamate synthase have also been identified in Z. mobilis, and could play a role in the conversion of ammonia to L-glutamine. Thus, the current study regarding $\mathrm{N}_{2}$ fixation along with our study regarding ammonia nitrogen utilization from manure in $Z$. mobilis will provide advantages for ethanol production through the utilization of a cheaper nitrogen source.

Mass balance of dairy manure-to-ethanol conversion process. As depicted in Fig. 8, under the optimal conditions of $\mathrm{NaOH}$ pretreatment and cellulose hydrolysis, $36.9 \mathrm{~kg}$ of ethanol was produced by Z. mobilis ZMT2 from $1000 \mathrm{~kg}$ of dried dairy manure. The other $62.7 \mathrm{~kg}$ of xylose was fermented by engineered yeast to theoretically produce $33.4 \mathrm{~kg}$ of ethanol. ${ }^{36}$ As the Z. mobilis used in this study was unable to convert xylose to ethanol, only a $36.9 \mathrm{~kg}$ ethanol yield was achieved from $1000 \mathrm{~kg}$ of dried dairy manure. When a xylose-utilization recombinant Z. mobilis strain, or another engineered strain, was used, the ethanol yield reached $70 \mathrm{~kg}$ from $1000 \mathrm{~kg}$ of dried dairy manure without an additional nitrogen source. This indicates that dairy manure could be used as an ideal biomass for ethanol fermentation in the future. 


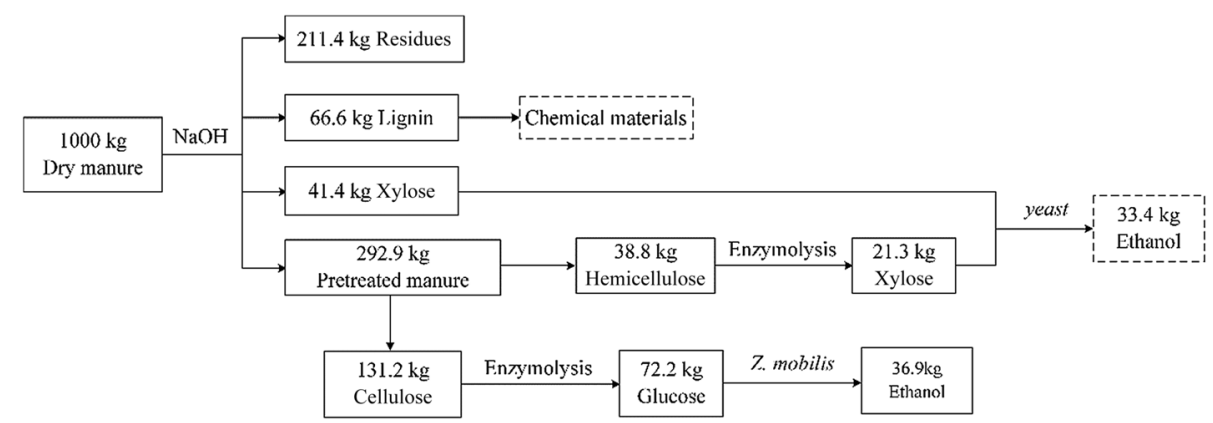

Fig. 8 Laboratory scale mass balance of dairy manure-to-ethanol conversion process.

\section{Conclusions}

In this study, we show that $\mathrm{NaOH}$ pretreatment can efficiently remove the barrier of lignocellulose, exposing cellulose and hemicellulose. Response surface method analysis determined the optimal conditions for the $\mathrm{NaOH}$ pretreatment were using a $6 \mathrm{~h}$ reaction time, a $140{ }^{\circ} \mathrm{C}$ temperature, a $1.34 \% \mathrm{NaOH}$ concentration, and a $100 \mathrm{~g} \mathrm{~L}^{-1}$ substrate concentration. Enzymatic hydrolysis was determined to be a key step in the transformation of cellulose and hemicellulose into soluble monosaccharides, such as glucose and xylose. Continuous enzymolysis was found to increase the glucose concentration to $19.84 \mathrm{~g} \mathrm{~L}^{-1}$, resulting in a good fermentation performance of $10.5 \mathrm{~g} \mathrm{~L}^{-1}$ ethanol and a $71.9 \%$ yield. Based on the results of the $\mathrm{NaOH}$ pretreatment, enzymatics, and ethanol fermentation, we also determined the degradation profile of manure cellulose and nitrogen resources that were utilized during ethanol fermentation. Taken together, these results demonstrate that dairy manure contains a suitable amount of carbon and nitrogen source for microbial growth. These results demonstrate the great potential of pretreatment, enzymatics and the fermentation process on ethanol production. Further research should be directed towards pentose fermentation and broadening the scope sugars that can be used.

\section{Conflicts of interest}

The authors declare that they have no competing interests.

\section{Authorship}

Mr YY carried out all experiments, participated in the study design and wrote the draft manuscript with the help of the other authors. MXH designed the whole study and improved the final manuscript. SL, YWW, BW, FRT, HQ, and QLZ participated in ethanol fermentation and mass balance. BW and FRT helped in the draft manuscript editing. ZYR, KDM, LCD, MZ and GQH participated in the discussion and helped in the manuscript editing. All authors read and approved the final manuscript.

\section{Funding information}

This research was financially supported by Sichuan Key Technology R\&D Program (Grant No. 2014NZ0045), the National
Natural Science Foundation of China (Grant No. 31570055), Youth Science and Technology Foundation of Sichuan Province (Grant No. 2015JQO047) and National Key Technology R\&D Program of China (Grant No. 2014BAD02B06-03) to Ming-Xiong He.

This research was partially supported by Special Fund for Agro-scientific Research in the Public Interest (201403019) and New Energy Program of Rural and Pastoral Areas from Science \& Technology Department of Qinghai Province (Grant No. 2015NN-E01) to Guo-Quan Hu.

\section{Availability of supporting data}

The strain Z. mobilis ZMT2 has been deposited at China General Microbiological Culture Collection Center (CGMCC) under the accession number CGMCC11888.

\section{Acknowledgements}

This research was financially supported by Youth Science and Technology Foundation of Sichuan Province (Grant No. 2015JQO047), the National Natural Science Foundation of China (Grant No. 31570055). Partially supported by Sichuan Key Technology R\&D Program (Grant No. 2014NZ0045), Special Fund for Agro-scientific Research in the Public Interest (201403019), New Energy Program of Rural and Pastoral Areas from Science \& Technology Department of Qinghai Province (Grant No. 2015-NN-E01) and National Key Technology R\&D Program of China (Grant No. 2014BAD02B06-03).

\section{References}

1 J. L. Rico, H. Garcia, C. Rico and I. Tejero, Bioresour. Technol, 2007, 98, 971-979.

2 B. Drosg, W. Fuchs, T. A. Seadi, M. Madsen and B. Linke, Nutrient Recovery by Biogas Digestate Processing, IEA Bioenergy, 2015, pp. 7-11.

3 W. Yao, X. Wu, J. Zhu, B. Sun and C. Miller, Trans. ASABE, 2009, 52, 2047-2054.

4 J. Sun, J. Zhu and W. Li, Biomass Bioenergy, 2012, 47, 442450.

5 W. Liao, Y. Liu, C. Frear and S. Chen, Bioresour. Technol, 2008, 99, 5859-5866. 
6 L. Wang, Y. Li, P. Chen, M. Min, Y. Chen, J. Zhu and R. R. Ruan, Bioresour. Technol., 2010, 101, 2623-2628.

7 Z. Wen, W. Liao and S. Chen, Bioresour. Technol., 2005, 96, 491-499.

8 Z. Wen, W. Liao and S. Chen, Process Biochem., 2005, 40, 3087-3094.

9 K. Mirahmadi, M. M. Kabir, A. Jeihanipour, K. Karimi and M. J. Taherzadeh, BioResources, 2015, 5, 928-938.

10 Y. Chen, M. A. Stevens, Y. Zhu, J. Holmes and H. Xu, Biotechnol. Biofuels, 2013, 6, 1-10.

11 M. Irfan, U. Asghar, M. Nadeem, R. Nelofer, Q. Syed, H. A. Shakir and J. I. Qazi, Waste Biomass Valorization, 2016, 1-8, DOI: 10.1007/s12649-016-9540-2.

12 C. Teater, Z. Yue, J. MacLellan, Y. Liu and W. Liao, Bioresour. Technol., 2011, 102, 1856-1862.

13 X. Zhang, J. Xu and J. J. Cheng, Energy Fuels, 2011, 25, 47964802.

14 J. Xu, X. Zhang and J. J. Cheng, Bioresour. Technol., 2012, 111, 255-260.

15 S. Chovau, D. Degrauwe and B. Van der Bruggen, Renewable Sustainable Energy Rev., 2013, 26, 307-321.

16 M. X. He, J. L. Wang, H. Qin, Z. X. Shui, Q. L. Zhu, B. Wu, F. R. Tan, K. Pan, Q. C. Hu, L. C. Dai, W. G. Wang, X. Y. Tang and G. Q. Hu, Carbohydr. Polym., 2014, 111, 645-654.

17 M. X. He, B. Wu, H. Qin, Z. Y. Ruan, F. R. Tan, J. L. Wang, Z. X. Shui, L. C. Dai, Q. L. Zhu, K. Pan, X. Y. Tang, W. G. Wang and Q. C. Hu, Biotechnol. Biofuels, 2014, 7, 101.

18 C. Chapple, M. Ladisch and R. Meilan, Nat. Biotechnol., 2007, 25, 746-748.

19 H. Li, N.-J. Kim, M. Jiang, J. W. Kang and H. N. Chang, Bioresour. Technol., 2009, 100, 3245-3251.

20 R. R. Patterson and D. D. Morgan, Europen Patent: EP 0085810 A2, 1982.
21 A. G. Woldesenbet, G. Shiferaw and B. S. Chandravanshi, Afr. J. Environ. Sci. Technol., 2013, 7, 435-440.

22 T. A. Kremer, B. LaSarre, A. L. Posto and J. B. McKinlay, Proc. Natl. Acad. Sci. U. S. A., 2015, 112, 2222-2226.

23 P. S. Panesar, S. S. Marwaha and J. F. Kennedy, J. Chem. Technol. Biotechnol., 2006, 81, 623-635.

24 H. K. Goering and P. J. Van Soest, Usda Agr Handb, 1970.

25 J.-L. Wang, B. Wu, H. Qin, Y. You, S. Liu, Z.-X. Shui, F.-R. Tan, Y.-W. Wang, Q.-L. Zhu, Y.-B. Li, Z.-Y. Ruan, K.-D. Ma, L.-C. D. Dai, G.-Q. Hu and M.-X. He, Microb. Cell Fact., 2016, 15, 1.

26 A. E. Goodman, P. L. Rogers and M. L. Skotnicki, Appl. Environ. Microbiol., 1982, 44, 496-498.

27 G. L. Miller, Anal. Chem., 1959, 31, 426-428.

28 Y.-C. He, Y. Ding, Y.-F. Xue, B. Yang, F. Liu, C. Wang, Z.-Z. Zhu, Q. Qing, H. Wu, C. Zhu, Z.-C. Tao and D.-P. Zhang, Bioresour. Technol., 2015, 193, 324-330.

29 T. Ponrasu, B. Manohar and S. Divakar, Process Biochem., 2009, 44, 251-255.

30 J. Wang, D. Q. Lu, Z. Hui, X. Q. Ling, B. Jiang and P. K. Ouyang, Afr. J. Biotechnol., 2009, 8, 1416-1424.

31 Y. Ding, J. Zheng, X. Xia, T. Ren and J. Kan, LWT-Food Sci. Technol., 2016, 67, 206-213.

32 K. Wilkinson, J. Lundkvist, G. Seisenbaeva and V. Kessler, Environ. Pollut., 2011, 159, 311-318.

33 Y. Koike, M. Z. An, Y. Q. Tang, T. Syo, N. Osaka, S. Morimura and K. Kida, J. Biosci. Bioeng., 2009, 108, 508-512.

34 D. Yang, L. Deng, D. Zheng, L. Wang and Y. Liu, J. Environ. Manage., 2016, 168, 87-93.

35 W. Liao, Y. Liu, C. Liu and S. Chen, Bioresour. Technol., 2004, 94, 33-41.

36 L. Tan, Z.-Y. Sun, S. Okamoto, M. Takaki, Y.-Q. Tang, S. Morimura and K. Kida, Biomass Bioenergy, 2015, 81, 265-272. 